\title{
Employing an urban meteorological network to monitor air temperature conditions in the 'local climate zones' of Szeged, Hungary
}

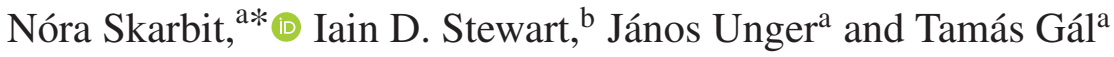 \\ ${ }^{a}$ Department of Climatology and Landscape Ecology, University of Szeged, Hungary \\ ${ }^{\mathrm{b}}$ Department of Civil Engineering, University of Toronto, Canada
}

\begin{abstract}
We analyse the average annual and seasonal air temperature conditions in the 'local climate zones' (LCZs) of Szeged, Hungary. The basis of our analysis is a 1-year dataset from 2014 to 2015 for a 20-station urban meteorological network. The network and its corresponding LCZ classes put temperature studies in Szeged into a new spatial framework to assess local climate and urban heat island (UHI) conditions. The stations were installed at locally representative sites using a Geographic Information System (GIS) method based on the standard surface parameters of the LCZ classification. The network was purposely designed to monitor thermal differences among LCZ classes in Szeged. We provide detailed site metadata for each of the monitoring stations used in the analysis. Our results show that the densely built-up LCZ classes have higher annual and monthly mean and minimum air temperatures than structurally open and more vegetated classes, with nocturnal differences of $>4{ }^{\circ} \mathrm{C}$ observed under calm, clear skies. Among select temperature indices measured in the urban LCZ classes, frost days, cooling degree-days, and tropical nights differ markedly from the background rural LCZ classes. This difference suggests that local climatologies exist within Szeged, and that these have implications for thermal comfort, urban energy use, and urban agriculture. Finally, the evaluation of heating and cooling rates in Szeged shows an important role for LCZs in UHI analysis.

KEY WORDS local climate zones; urban heat island; urban meteorological network; temperature indices; heating and cooling rates
\end{abstract}

Received 18 March 2016; Revised 11 January 2017; Accepted 15 January 2017

\section{Introduction}

The Earth's surface and its atmospheric boundary-layer change continuously through time and space. Thus the heat budget at the Earth's surface also changes, in part due to its surface structure, moisture, and radiative characteristics. In urban environments, the surface is characteristically dry, impervious, and rough, by way of its defining features such as buildings, trees, and industrial structures. These features, and the atmospheric processes that they modify, contribute to the formation of 'urban' climates as distinct from rural, natural, or regional climates (Oke, 1987). To observe urban and rural climates typically involves comparative measurements in the city and its neighbouring lands, whether agricultural or unmanaged. Investigators must control these measurements for non-urban influences, such as surface relief and prevailing weather, so as to isolate an 'urban' signal (Lowry, 1977; Stewart, 2011a). However, the spatial demarcation between 'urban' and 'rural' is often not clear, making the placement and classification of instruments to observe urban and rural climates somewhat problematic. Even within urban and rural areas

\footnotetext{
* Correspondence to: N. Skarbit, Department of Climatology and Landscape Ecology, University of Szeged, Egyetem street 2, Szeged 6722, Hungary. E-mail: skarbitn@geo.u-szeged.hu
}

that are easily demarcated, surfaces are diverse and properties vary across micro (tens to hundreds of metres) and local (hundreds to thousands of metres) horizontal scales, creating spatial changes in near-surface climate.

These challenges in urban climatology highlight the need to classify urban and rural surfaces at finer scales, and according to local climatic influences (e.g. Auer, 1978; Oke, 2004). Responding to this need, Stewart and Oke (2012) developed the 'local climate zone' (LCZ) system, a climate-based classification of urban and rural measuring sites and their surrounding landscapes. The system is applicable to most cities and is intended for urban temperature studies using screen-height thermal sensors. The LCZ system classifies the urban-rural landscape into ten 'built' and seven 'land cover' classes, each distinguished by a characteristic range of values for measurable surface parameters, such as sky view factor, pervious surface fraction, building height and spacing, surface thermal admittance, and anthropogenic heat flux. These parameters characterize the thermal, radiative, moisture, and aerodynamic properties of the surface (Oke, 2004). For photographs and physical properties of the LCZ classes, readers can consult the supplementary datasheets in Stewart and Oke (2012). The primary aim of the LCZ scheme is to promote consistent reporting of site metadata, and to standardize inter-site air temperature comparisons. As 
such, the urban heat island (UHI) can be defined as an air temperature difference between pairs of LCZ classes $\left(\Delta T_{\mathrm{LCZ} X-Y}\right)$ (Stewart et al., 2014).

A derivative, and increasingly popular, use of the LCZ classification system is to map urban and rural areas according to their surface structure and land cover properties. Methodologies have been developed and shown to provide informative maps of cities worldwide, depicting spatial patterns of surface form and cover in standardized, climatically relevant terms (Bechtel et al., 2015). The maps are therefore amenable to inter-study comparison and to global environmental issues such as the UHI effect. One of the first LCZ maps to be produced was for Novi Sad, Serbia (Unger et al., 2011). In that study, the LCZ contours were determined from similarities with the standard classes of Stewart and Oke (2012), as determined by aerial photography and local expert knowledge. More recently, LCZ maps have been produced for numerous other cities using more sophisticated methods, both manual and automated (e.g. Bechtel and Daneke, 2012; Alexander and Mills, 2014; Lelovics et al., 2014). These methods are discussed in detail in Bechtel et al. (2015).

Supporting the LCZ mapping effort is a growing literature on LCZ temperature observations (e.g. Siu and Hart, 2013; Lehnert et al., 2014; Fenner et al., 2014; Stewart et al., 2014; Unger et al., 2014; Leconte et al., 2015a). Each study provides a test of the theoretically expected thermal differences between LCZ classes. As reported, the temperature differences $\left(\Delta T_{\mathrm{LCZ} X-Y}\right)$ are most pronounced during calm, clear nights, and between structurally dissimilar classes.

In this study, we analyse a 1-year air temperature dataset from 20 urban meteorological stations of the urban meteorological network in the city of Szeged, Hungary (URBAN-PATH, 2015). The original network consists of 24 stations, but 4 of them were excluded from the analysis because of data gaps and technical reasons. The purpose of the study is to determine the extent to which LCZs in Szeged exhibit unique thermal climates, and to assess the robustness of the LCZ scheme with empirical data from a medium-sized European city. Our prototype network was designed and installed according to LCZ guidelines in Stewart and Oke (2012). Moreover, its configuration is sufficiently dense to cover a range of LCZ classes, and its period of observation is suitably long to document seasonal changes in LCZ behaviour. The station network provides a temperature dataset of high temporal and spatial resolution across various weather conditions and patterns. The data are therefore superior to previous mobile measurements made in Szeged (Unger et al., 2001; Unger, 2009). Furthermore, the current work puts temperature studies in Szeged into a new experimental framework (LCZ), as one which is standardized and based on physical urban climatology. Our specific objectives are therefore (1) to report the site characteristics of the network stations and their local surroundings; (2) to evaluate the average annual and seasonal temperature conditions of LCZs in both 'ideal' and general weather conditions; and (3) to examine the nocturnal temperature dynamics of LCZ classes for selected 'ideal' days.
In meeting these objectives, we uncover some lesser studied features of the LCZ scheme, such as the occurrence of frost days, cooling degree-days (CDD), and tropical nights within the city, and bridge these features to the interests of urban residents, city planners, and utility managers.

\section{Distribution of ' $\mathrm{LCZs}$ ' and the urban meteorological network in Szeged}

Szeged is located in southeastern Hungary $\left(46^{\circ} \mathrm{N}, 20^{\circ} \mathrm{E}\right)$. As part of the Great Hungarian Plain, its terrain is almost completely flat with an average height of $79 \mathrm{~m}$ a.s.1. The River Tisza crosses the city on its southeast side (Figure 1). According to the Köppen climate classification, Szeged has a Cfb climate - temperate and warm with a uniform annual distribution of precipitation (Kottek et al., 2006). The mean annual temperature is $10.4^{\circ} \mathrm{C}$, and precipitation averages $497 \mathrm{~mm}$ per year. The urbanized area is $\sim 40 \mathrm{~km}^{2}$ with a population of 162000 . Szeged is characterized by a densely built midrise core, with openly spaced blocks of flats in the northern part of the city, as well as family homes and warehouses on the outskirts (Unger et al., 2001). The rural surroundings are mostly croplands (wheat, maze) with few scattered trees.

To apply the LCZ system to the study area, that is, to draw boundaries of the zones occurring therein, an automated GIS method was used (see Lelovics et al., 2014). To assess the accuracy of the final LCZ map, we compared it to the mapping method of Bechtel et al. (2015), and found that differences were minor (Skarbit and Gál, 2016). As the study area covers $8.6 \times 6.7 \mathrm{~km}$ of land (Figure 1), we concentrated only on the most typical built types without applying further sub-classification. This gave us sufficiently large LCZ areas to work within, and an easily interpretable map. Compact buildings (LCZs 2 and 3) and open-set/low-rise buildings (LCZs 6, 8, and 9) exist mainly in central and outlying areas, respectively. Compact midrise buildings (LCZ 5) exist in both inner and ex-central parts of the city. On the periphery are large areas of sparse settlement (LCZ 9), where the landscape changes from urban to rural uses (LCZ D).

With this configuration of LCZ classes, we established a meteorological network of 20 stations (1 station $/ 2.9 \mathrm{~km}^{2}$ ) to monitor long-term temperature and humidity conditions in Szeged at a spatial resolution that can detect thermal differences among single neighbourhoods, and whose temporal resolution can detect diurnal and seasonal peculiarities in local climate (Unger et al., 2015). To meet this aim, we installed automatic data loggers and transmission systems across the urban-rural area. Output from this network provides real-time information (e.g. temperature and humidity maps and plots) for local institutions, governments, health authorities, heating suppliers, and the general public.

To ensure representative siting of stations within the delineated LCZ areas (Figure 1), each station was placed at least several hundred metres from the border of the LCZ zone within which it was located, and in locations whose micro-scale environments were deemed to be typical (in 


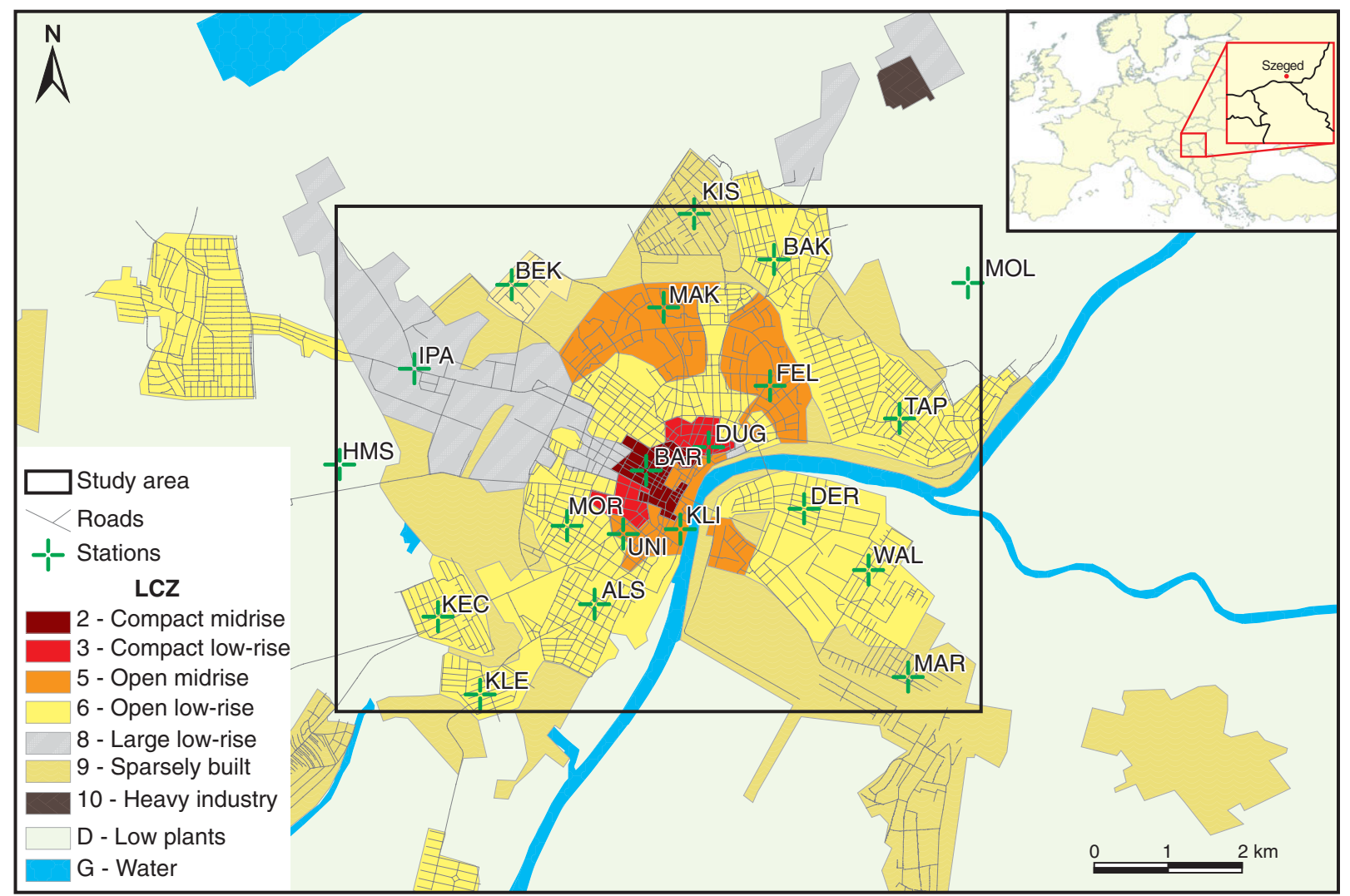

Figure 1. LCZ map and station locations of the urban meteorological network in Szeged (see Tables 1, 2 and 3 for station metadata).

terms of surface cover and geometry) of the local surroundings. These judgements were based on information gathered from foot surveys, land cover maps, and aerial photographs. In this process, we took into consideration the ability of the entire network to reproduce the spatial patterns of mean temperature as estimated by an empirical model (Balázs et al., 2009). Measurements at each site were made with Sensirion SHT25 sensors housed in naturally ventilated radiation screens $(220 \times 310 \mathrm{~mm})$ fixed $60 \mathrm{~cm}$ from a console. The screens are identical to those used by the Hungarian Meteorological Service (HMS). The accuracy of the temperature sensors is $\pm 0.4^{\circ} \mathrm{C}$ in the range -20 to $+80^{\circ} \mathrm{C}$. Calibrations were performed by the manufacturer of the stations. The consoles were mounted to lamp posts at a height of $4 \mathrm{~m}$ above ground (sensor elevations range from 82 to $87 \mathrm{~m}$ a.s.1.). We assume that air temperatures at 2 and $4 \mathrm{~m}$ above ground are nearly equal, based on work by Nakamura and Oke (1988), who found that the air inside the urban surface layer remains unstable during the day, and that mixing of air parcels at different levels is assured. For further technical details about the sensors, the logging and transmission equipment, and online displaying of the data, see Unger et al. (2015).

Two stations represent the rural area, which we classify as 'low plants' (LCZ D), while the remaining 18 represent variously built-up areas of the city: 'compact midrise' (LCZ 2) and 'compact low-rise' (LCZ 3) each have one station; 'open midrise' (LCZ 5) has four stations; 'open low-rise' (LCZ 6) has nine stations; 'large low-rise' (LCZ 8) has one station; and 'sparsely built' (LCZ 9) has two stations (Figure 1). To gather site metadata for each station (Tables 1-3), building surface fraction (BSF) and height of roughness elements (HRE) were calculated using a 3D building database for Szeged (Gál et al., 2009; Unger, 2009). This vector-based dataset was established using cadastral building footprints and photogrammetric height measurements, with horizontal and vertical precisions of about 10 and $50 \mathrm{~cm}$, respectively. Determining the mean HRE involved a simple database query. Mean sky view factor (SVF) for the sites was calculated from a 5-m resolution point grid, using a vector-based method from the building database (Gál et al., 2009; Unger, 2009). Calculations of impervious and pervious surface fractions were more problematic. Proper values can be measured with detailed geodesic measurements; however, in urban areas these measurements are time consuming (e.g. in private courtyards). A less precise but more feasible approach is to use high-resolution satellite images and multiple urban datasets. In our case, we applied 5-m resolution RapidEye satellite imagery, 1:25000 topographic maps, a road database, and a CORINE Land Cover database. From the satellite image, NDVI values were calculated first, then the vegetated pixels [regarded as pervious surface fraction (PSF)] were identified, and finally the classification was refined using other data sources (Lelovics et al., 2014). Impervious surface fraction (ISF) was defined as $1-(\mathrm{BSF}+\mathrm{PSF})$. For all geometric and surface cover properties, mean values were calculated for each station's 'circle of influence,' to which we assigned a radius of $250 \mathrm{~m}$. The radius is based on results from observational 
Table 1. Site metadata for urban meteorological stations in LCZs 2, 3, and 5.

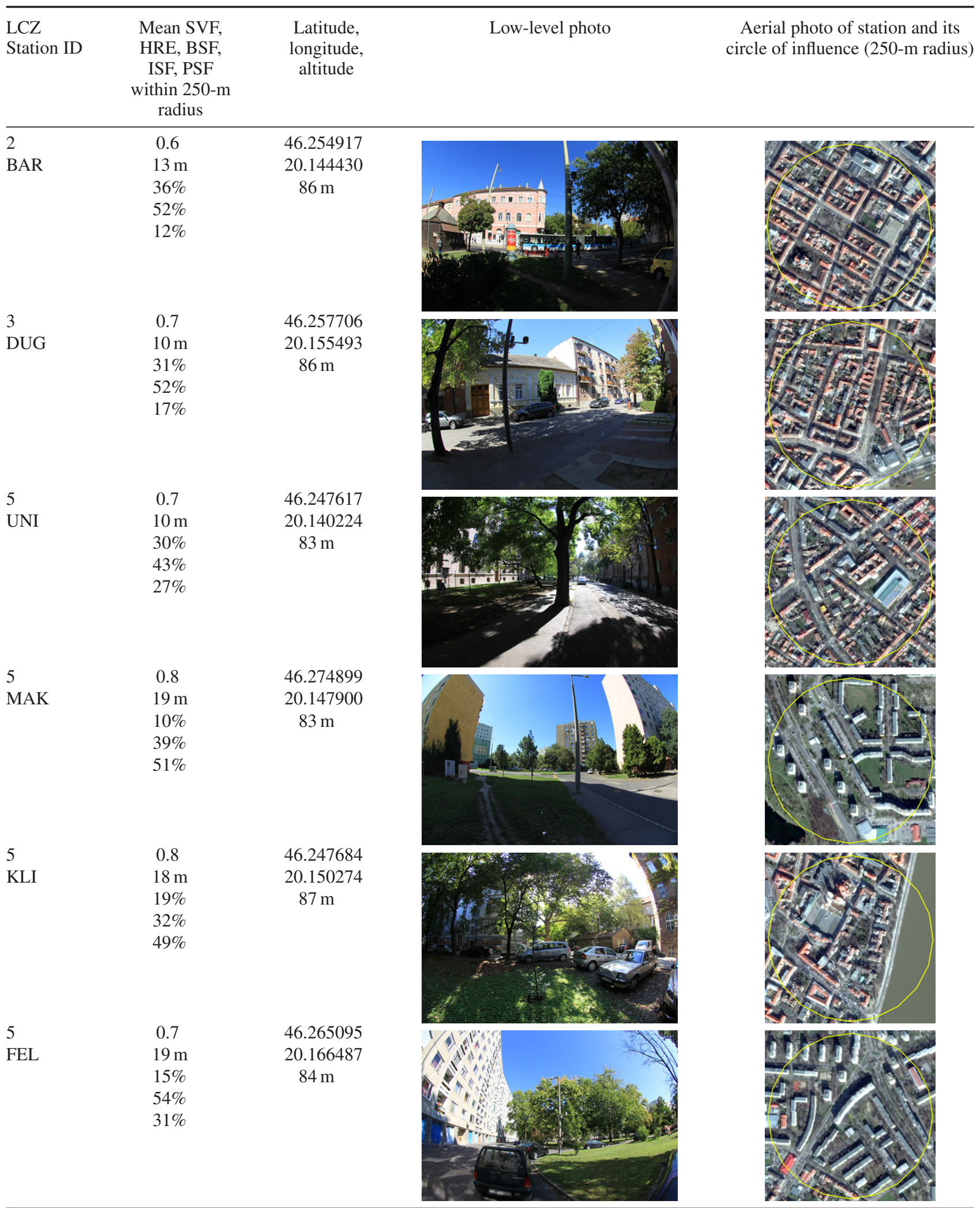

BSF, buildings surface fraction; HRE, height of roughness elements (including vegetation and buildings); ISF, impervious surface fraction; PSF, pervious surface fraction (including water); SVF, sky view factor (excluding vegetation). 
Table 2. The same as Table 1 but for stations in LCZ 6 .

\begin{tabular}{|c|c|c|c|c|}
\hline $\begin{array}{l}\text { LCZ } \\
\text { Station ID }\end{array}$ & $\begin{array}{c}\text { Mean SVF, } \\
\text { HRE, BSF, } \\
\text { PSF, ISF } \\
\text { in a radius } \\
\text { of } 250 \mathrm{~m}\end{array}$ & $\begin{array}{l}\text { Latitude, } \\
\text { longitude, } \\
\text { altitude }\end{array}$ & Low-level photo & $\begin{array}{c}\text { Aerial photo around the station in } \\
\text { a radius of } 250 \mathrm{~m}\end{array}$ \\
\hline $\begin{array}{l}6 \\
\text { KEC }\end{array}$ & $\begin{array}{l}0.9 \\
5 \mathrm{~m} \\
16 \% \\
41 \% \\
43 \%\end{array}$ & $\begin{array}{l}46.237644 \\
20.107697 \\
84 \mathrm{~m}\end{array}$ & & 8 \\
\hline $\begin{array}{l}6 \\
\text { KLE }\end{array}$ & $\begin{array}{l}0.9 \\
6 \mathrm{~m} \\
15 \% \\
43 \% \\
42 \%\end{array}$ & $\begin{array}{l}46.227776 \\
20.114578 \\
81 \mathrm{~m}\end{array}$ & & $\frac{5}{\frac{5}{6}} \frac{5}{6}$ \\
\hline $\begin{array}{l}6 \\
\text { BEK }\end{array}$ & $\begin{array}{l}0.9 \\
6 \mathrm{~m} \\
10 \% \\
29 \% \\
61 \%\end{array}$ & $\begin{array}{l}46.277939 \\
20.121138 \\
83 \mathrm{~m}\end{array}$ & & 1. \\
\hline $\begin{array}{l}6 \\
\text { MOR }\end{array}$ & $\begin{array}{l}0.9 \\
6 \mathrm{~m} \\
18 \% \\
49 \% \\
33 \%\end{array}$ & $\begin{array}{l}46.259476 \\
20.127237 \\
84 \mathrm{~m}\end{array}$ & & $\frac{10}{4}$ \\
\hline $\begin{array}{l}6 \\
\text { ALS }\end{array}$ & $\begin{array}{l}0.8 \\
7 \mathrm{~m} \\
21 \% \\
50 \% \\
29 \%\end{array}$ & $\begin{array}{l}46.238625 \\
20.135008 \\
85 \mathrm{~m}\end{array}$ & & $\begin{array}{r}8 \\
4 \\
4\end{array}$ \\
\hline $\begin{array}{l}6 \\
\text { BAK }\end{array}$ & $\begin{array}{l}0.9 \\
5 \mathrm{~m} \\
17 \% \\
42 \% \\
41 \%\end{array}$ & $\begin{array}{l}46.280277 \\
20.167339 \\
83 \mathrm{~m}\end{array}$ & & (5.) \\
\hline $\begin{array}{l}6 \\
\text { DER }\end{array}$ & $\begin{array}{l}0.8 \\
7 \mathrm{~m} \\
19 \% \\
47 \% \\
34 \%\end{array}$ & $\begin{array}{l}46.249966 \\
20.172155 \\
83 \mathrm{~m}\end{array}$ & & 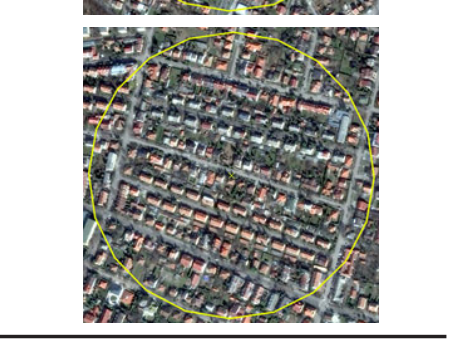 \\
\hline
\end{tabular}


Table 2. Continued.

\begin{tabular}{|c|c|c|c|c|}
\hline $\begin{array}{l}\text { LCZ } \\
\text { Station ID }\end{array}$ & $\begin{array}{c}\text { Mean SVF, } \\
\text { HRE, BSF, } \\
\text { PSF, ISF } \\
\text { in a radius } \\
\text { of } 250 \mathrm{~m}\end{array}$ & $\begin{array}{c}\text { Latitude, } \\
\text { longitude, } \\
\text { altitude }\end{array}$ & Low-level photo & $\begin{array}{c}\text { Aerial photo around the station in } \\
\text { a radius of } 250 \mathrm{~m}\end{array}$ \\
\hline 6 & 0.9 & 46.242348 & & \\
\hline WAL & $\begin{array}{l}7 \mathrm{~m} \\
16 \% \\
47 \% \\
37 \%\end{array}$ & $\begin{array}{l}20.183384 \\
82 \mathrm{~m}\end{array}$ & & 8 \\
\hline 6 & 0.8 & 46.260876 & & \\
\hline TAP & $\begin{array}{l}7 \mathrm{~m} \\
18 \% \\
46 \% \\
36 \%\end{array}$ & $\begin{array}{l}20.189226 \\
82 \mathrm{~m}\end{array}$ & & \\
\hline
\end{tabular}

studies of land use effects on screen-height air temperature (e.g. Mizuno et al., 1990/1991; Runnalls and Oke, 2006).

For some stations, the values of surface parameters (mostly building and ISFs) fall outside the standard LCZ ranges given by Stewart and Oke (2012) (Table 4). This can be attributed partly to the applied mapping process (Lelovics et al., 2014). The basic spatial units of the method are the 'lot area polygons', which are defined by building blocks. Each point of one lot polygon is closer to the centre building block than to any other block. The GIS method classifies these lot area polygons into their most similar LCZ class using a scoring system. During the scoring process, inevitably there are a few parameter values of the polygon that lie outside the standard range of an LCZ class. Polygons assigned to similar LCZ classes were aggregated to a minimum size, as defined by 'local' horizontal scales (i.e. $10^{2}-10^{4} \mathrm{~m}$ ).

The thermal effects of water bodies in the study area are minimal. In the case of KLI station, the River Tisza lies $157 \mathrm{~m}$ to the east. However, the thermal effects of the river are expected to be negligible at KLI because the station is blocked from the river's influence by compact buildings and a river levee. Moreover, the elevation of the river water is $5-10 \mathrm{~m}$ below that of the station.

\section{Methods}

\subsection{Data preparation and analysis periods}

We calculated 10-min averages of air temperature $(T)$ based on measurements taken at 1-min intervals for 365 days (1 June 2014-31 May 2015). To compare the thermal behaviour of different LCZ classes in Szeged, we used average values measured at the stations within one LCZ type. Accordingly, these values can represent the 'average' of one station (e.g. LCZ 2), or the average of nine stations (e.g. LCZ 6), depending on the distribution of sites and LCZ classes across Szeged. To isolate and quantify urban effects on local thermal climate, extraneous influences on air temperature, such as relief and non-synchronous measurement, must be controlled (Lowry, 1977; Stewart, 2011a). Our dataset meets these important experimental criteria. We concentrated our data analysis on sunset and night-time hours when urban-rural and intra-urban differences in near-surface air temperature are most pronounced (Oke, 1987). Our analysis was based firstly on the 20-station temperature dataset for each day of the 1-year study period, regardless of regional weather conditions. Thereafter we selected only those days which had 'ideal' weather (i.e. clear skies, weak winds) for the formation of heat islands and local thermal climates.

Our selection of 'ideal' days derives from the weather factor, $\Phi_{w}$, developed by Oke (1998):

$$
\Phi_{w}=u^{-\frac{1}{2}} \cdot\left(1-k n^{2}\right)
$$

where $u$ is the wind speed $\left(\mathrm{m} \mathrm{s}^{-1}\right), k$ is the Bolz correction factor for cloud height (Bolz, 1949), and $n$ is the cloud amount in tenths. $\Phi_{w}$ measures the extent to which sky and wind conditions allow for nocturnal cooling of the surface. Its values were calculated at 1-h intervals using regional cloud and wind data from station HMS. The obtained values were averaged from sunrise to sunrise $(24 \mathrm{~h})$ so as to capture the daytime (i.e. antecedent) weather conditions that promote or supress local climate formation in the city. Using a threshold of $\Phi_{w}>0.5$, we found 108 'ideal' days. With higher thresholds of $\Phi_{w}>0.6$ and $\Phi_{w}>0.7$, we found 64 and 32 days, respectively. Finally, to isolate the very specific weather and soil conditions that promote local climate formation, and to be consistent with LCZ observations reported in Stewart et al. (2014), we 
Table 3. The same as Table 1 but for stations in LCZs 8, 9, and D.

\begin{tabular}{|c|c|c|c|c|}
\hline $\begin{array}{l}\text { LCZ } \\
\text { Station ID }\end{array}$ & $\begin{array}{l}\text { Mean SVF, } \\
\text { HRE, BSF, } \\
\text { PSF, ISF } \\
\text { within } 250-m \\
\text { radius }\end{array}$ & $\begin{array}{l}\text { Latitude, } \\
\text { longitude, } \\
\text { altitude }\end{array}$ & Low-level photo & $\begin{array}{l}\text { Aerial photo of station and its } \\
\text { circle of influence (250-m radius) }\end{array}$ \\
\hline $\begin{array}{l}8 \\
\text { IPA }\end{array}$ & $\begin{array}{l}0.9 \\
5 \mathrm{~m} \\
12 \% \\
48 \% \\
40 \%\end{array}$ & $\begin{array}{c}46.267803 \\
20.103786 \\
84 \mathrm{~m}\end{array}$ & & $=\frac{15}{(5-2)}$ \\
\hline $\begin{array}{l}9 \\
\text { KIS }\end{array}$ & $\begin{array}{l}0.9 \\
5 \mathrm{~m} \\
5 \% \\
17 \% \\
78 \%\end{array}$ & $\begin{array}{c}46.280277 \\
20.167339 \\
83 \mathrm{~m}\end{array}$ & & \\
\hline $\begin{array}{l}9 \\
\text { MAR }\end{array}$ & $\begin{array}{l}0.9 \\
5 \mathrm{~m} \\
5 \% \\
18 \% \\
77 \%\end{array}$ & $\begin{array}{c}46.229160 \\
20.190094 \\
83 \mathrm{~m}\end{array}$ & & 2 \\
\hline $\begin{array}{l}\text { D } \\
\text { HMS }\end{array}$ & $\begin{array}{l}1 \\
1 \mathrm{~m} \\
0 \% \\
1 \% \\
99 \%\end{array}$ & $\begin{array}{c}46.256165 \\
20.090342 \\
82 \mathrm{~m}\end{array}$ & & \\
\hline $\begin{array}{l}\text { D } \\
\text { MOL }\end{array}$ & $\begin{array}{l}0.9 \\
1 \mathrm{~m} \\
1 \% \\
4 \% \\
95 \%\end{array}$ & $\begin{array}{c}46.277348 \\
20.201660 \\
82 \mathrm{~m}\end{array}$ & & \\
\hline
\end{tabular}

used $\Phi_{w}>0.7$ to define 'ideal' days for local climates to develop. According to weather reports from station HMS, these 32 days were without precipitation.

Comparing the 1-year study period to the climate normals of 1981-2010 at station HMS, the period can be described as warmer than the 30 -year mean $\left(+1^{\circ} \mathrm{C}\right)$, primarily due to the warmer winter $\left(+2.4^{\circ} \mathrm{C}\right)$, although autumn and spring were also milder $\left(+1.5\right.$ and $+0.5^{\circ} \mathrm{C}$, respectively). The summer of 2014 was only slightly cooler $\left(-0.3^{\circ} \mathrm{C}\right)$ than the 30 -year normal. We do not expect these seasonal departures to undermine the representativeness of our results.

\subsection{Temperature-based indices}

Daily temperature indices measure the numbers of days above or below a threshold temperature for a specified time, duration, and purpose (e.g. for building heating and cooling, or outdoor gardening). The number of annual 'frost days', for example, is the sum of all days within a given year having a daily minimum air temperature below $0^{\circ} \mathrm{C}$. Other indices have different threshold temperatures but are calculated in a similar way (see Table 6). We supplement these indices with heating and cooling degree-days (HDD and CDD), which measure the demand for building energy. HDD and CDD calculations 
Table 4. Surface property values for 'local climate zones' (source: Stewart and Oke (2012)).

\begin{tabular}{|c|c|c|c|c|}
\hline LCZ: Local climate zone & $\begin{array}{l}\text { Sky view } \\
\text { factor }^{\mathrm{a}}\end{array}$ & $\begin{array}{l}\text { Building surface } \\
\text { fraction }^{\mathrm{b}}\end{array}$ & $\begin{array}{l}\text { Impervious surface } \\
\text { fraction }^{c}\end{array}$ & $\begin{array}{l}\text { Height of roughness } \\
\text { elements }^{\mathrm{d}}\end{array}$ \\
\hline LCZ 1: Compact high-rise & $0.2-0.4$ & $40-60$ & $40-60$ & $>25$ \\
\hline LCZ 2: Compact midrise & $0.3-0.6$ & $40-70$ & $30-50$ & $10-25$ \\
\hline LCZ 3: Compact low-rise & $0.2-0.6$ & $40-70$ & $20-50$ & $3-10$ \\
\hline LCZ 4: Open high-rise & $0.5-0.7$ & $20-40$ & $30-40$ & $>25$ \\
\hline LCZ 5: Open midrise & $0.5-0.8$ & $20-40$ & $30-50$ & $10-25$ \\
\hline LCZ 6: Open low-rise & $0.6-0.9$ & $20-40$ & $20-50$ & $3-10$ \\
\hline LCZ 7: Lightweight low-rise & $0.2-0.5$ & $60-90$ & $<20$ & $2-4$ \\
\hline LCZ 8: Large low-rise & $>0.7$ & $30-50$ & $40-50$ & $3-10$ \\
\hline LCZ 9: Sparsely built & $>0.8$ & $10-20$ & $<20$ & $3-10$ \\
\hline LCZ 10: Heavy industry & $0.6-0.9$ & $20-30$ & $20-40$ & $5-15$ \\
\hline LCZ A: Dense trees & $<0.4$ & $<10$ & $<10$ & $3-30$ \\
\hline LCZ B: Scattered trees & $0.5-0.8$ & $<10$ & $<10$ & $3-15$ \\
\hline LCZ C: Bush, scrub & $0.7-0.9$ & $<10$ & $<10$ & $<2$ \\
\hline LCZ D: Low plants & $>0.9$ & $<10$ & $<10$ & $<1$ \\
\hline LCZ E: Bare rock or paved & $>0.9$ & $<10$ & $>90$ & $<0.25$ \\
\hline LCZ F: Bare soil or sand & $>0.9$ & $<10$ & $<10$ & $<0.25$ \\
\hline LCZ G: Water & $>0.9$ & $<10$ & $<10$ & - \\
\hline
\end{tabular}

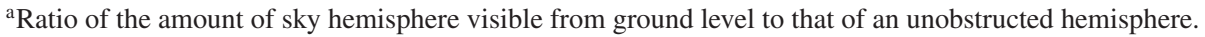

${ }^{b}$ Proportion of ground surface with building cover $(\%)$.

${ }^{\mathrm{c}}$ Proportion of ground surface with impervious cover (rock, paved) (\%).

${ }^{\mathrm{d}}$ Geometric average of building heights (LCZs 1-10) and tree/plant heights (LCZs A-F) (m).

Table 5. Annual, summer, and winter air temperatures $\left({ }^{\circ} \mathrm{C}\right)$ and standard deviation among stations according to LCZ classes in Szeged (June 2014-May 2015).

\begin{tabular}{|c|c|c|c|c|c|c|c|}
\hline \multirow[t]{2}{*}{ Mean temperature (2014-2015) } & \multicolumn{7}{|c|}{ LCZ class (number of stations per class) } \\
\hline & $\begin{array}{c}2 \\
(1)\end{array}$ & $\begin{array}{c}3 \\
(1)\end{array}$ & $\begin{array}{c}5 \\
(4)\end{array}$ & $\begin{array}{c}6 \\
(9)\end{array}$ & $\begin{array}{c}8 \\
(1)\end{array}$ & $\begin{array}{c}9 \\
(2)\end{array}$ & $\begin{array}{l}D \\
(2)\end{array}$ \\
\hline Annual mean & 13.2 & 13.2 & 13.0 & 12.8 & 12.3 & 12.6 & 12.3 \\
\hline (standard deviation) & $(-)$ & $(-)$ & $(0.11)$ & $(0.13)$ & $(-)$ & $(0.14)$ & $(0.21)$ \\
\hline Summer mean & 22.2 & 22.2 & 21.9 & 21.7 & 21.5 & 21.5 & 21.1 \\
\hline (standard deviation) & $(-)$ & $(-)$ & $(0.09)$ & $(0.15)$ & $(-)$ & $(0.35)$ & $(0.35)$ \\
\hline Summer maximum & 35.2 & 34.4 & 33.9 & 34.7 & 34.5 & 34.7 & 34.7 \\
\hline Summer minimum & 10.8 & 11.3 & 8.8 & 7.9 & 9.8 & 8.7 & 6.9 \\
\hline Winter mean & 3.6 & 3.6 & 3.6 & 3.2 & 3.2 & 3.3 & 2.9 \\
\hline (standard deviation) & $(-)$ & $(-)$ & $(0.08)$ & $(0.14)$ & $(-)$ & $(0.21)$ & $(0.28)$ \\
\hline Winter maximum & 14.6 & 14.1 & 14.1 & 14.5 & 14.3 & 14.5 & 14.4 \\
\hline Winter minimum & -7.0 & -7.0 & -7.9 & -7.9 & -8.2 & -8.2 & -8.6 \\
\hline
\end{tabular}

are based on the formulae used in Matzarakis and Thomsen (2009).

\section{Results}

\subsection{Inter-class LCZ comparisons}

\subsubsection{General temperature conditions}

Annual, summer, and winter temperatures during the 1-year study period in Szeged vary with LCZ classes (Table 5). For mean temperature $\left(T_{\text {mean }}\right)$, the tendency is clear: the values decrease as the buildings become less compact and lower in height, with large differences in summer $\left(\Delta T_{\mathrm{LCZ} 2-\mathrm{LCZD}}=1.1^{\circ} \mathrm{C}\right)$ and smaller differences in winter $\left(\Delta T=0.7^{\circ} \mathrm{C}\right)$. For the maximum temperature $\left(T_{\max }\right)$ values, no clear trend is detectable among the LCZ classes, although LCZ 2 is the warmest class in both summer and winter (Table 5). In the case of minimum temperature $\left(T_{\min }\right)$, the compact and centrally located LCZs are generally warmer than open and outlying LCZs, with the largest difference of $4.4{ }^{\circ} \mathrm{C}$ occurring in summer between LCZs 3 and D. In winter, the difference between these same classes is much smaller $\left(1.6^{\circ} \mathrm{C}\right)$. Within the built-up area of Szeged, intra-urban differences in $T_{\text {min }}$ are pronounced: comparing compact low-rise to open low-rise $\left(\Delta T_{\text {LCZ 3-LCZ } 6}\right)$ in summer, the difference is $3.4^{\circ} \mathrm{C}$; and comparing compact midrise to open midrise $\left(\Delta T_{\mathrm{LCZ} 2-\mathrm{LCZ} 5}\right)$, the difference is $2.0^{\circ} \mathrm{C}$. For winter $T_{\min }$, the difference between compact midrise and large low-rise $\left(\Delta T_{\mathrm{LCZ} 2-\mathrm{LCZ} 8}\right)$ is $1.2^{\circ} \mathrm{C}$.

To further extend our investigation into LCZ temperatures, we examined three summer months (June to August) when solar irradiation and energy exchange processes are more intensive, and when thermal reactions of built and natural surfaces are more distinctive. We used the means of daily ( $24 \mathrm{~h}$ ), diurnal (sunrise to sunset), and nocturnal (sunset to sunrise) temperatures in LCZ classes for 'ideal' days in summer $(n=12)$ (Figure 2). Daylight periods are 


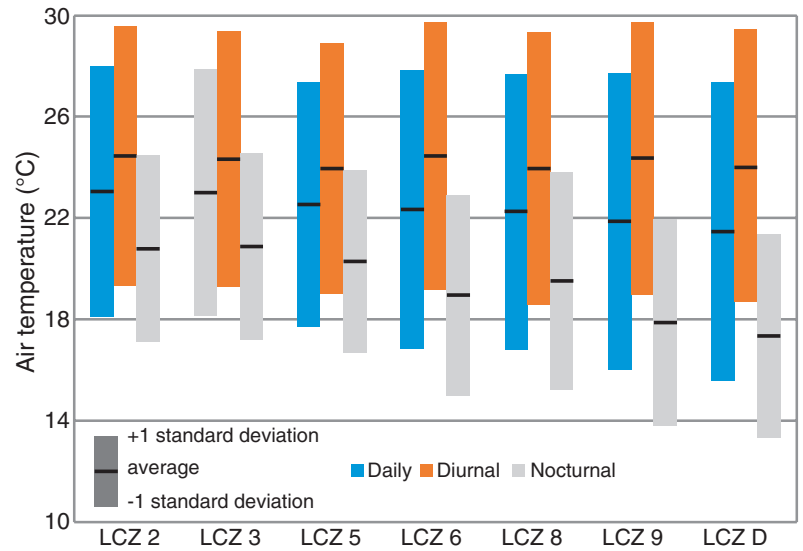

Figure 2. Means of daily (24h), diurnal (sunrise to sunset), and nocturnal (sunset to sunrise) air temperatures in LCZ classes for ideal days $(n=12)$ in summer (June-August 2014).

appreciably longer than nocturnal ones in summer (daylight, 63\%; night, 37\%), and thus temperature values measured during daylight hours dominate the calculation of daily means.

We observed negligible inter-class variations among diurnal LCZ averages in summer (roughly equal to or less than the measurement accuracy of the temperature sensors, at $\pm 0.4{ }^{\circ} \mathrm{C}$ ) (Figure 2 ). For the daily values, the differences are slightly greater, but not more than $1.5^{\circ} \mathrm{C}$. However, at night the temperature differences between centrally located and outlying LCZ classes are clear, and can exceed $3.5^{\circ} \mathrm{C}$. LCZs 2,3 , and 5 record the highest temperatures, while LCZs 6 and 8 are intermediate, and LCZs 9 and D the lowest. We therefore observe that during hot and sunny summer weather (with occasional heat waves) in Szeged, inter-class LCZ temperature difference are negligible during the day, but nocturnal temperatures in densely built areas (LCZs 2 and 3) remain elevated above those of open and vegetated areas (LCZs 6 and 9).

\subsubsection{Daily temperature indices}

Our results for the temperature indices of the 1-year study period suggest that LCZs have different thermal climatologies in Szeged (Table 6; Figure 3). A good example of this is CDD, which indicates urban energy demand for space cooling, and which increase by $40 \%$ from LCZ 8 to LCZ 3 (Figure 3). In the case of heating days, the difference between LCZ 2 and LCZ D is 13 days, which corresponds to a $10 \%$ increase in heating demand (HDD) from city centre to surrounding rural areas.

Frost days are especially important to residential and commercial gardening, and to city road maintenance. From the more compact LCZ areas to natural and open areas, the number of days measured by the 'cold' indices (i.e. those indicating low temperatures) increases. For example, the number of frost days differs by $20-30 \%$ among LCZ classes within the city, and by $40 \%$ among classes between city and countryside (Figure 3). In 2014-2015, we observed 25 more frost days in the countryside of Szeged (LCZ D), compared with its city centre (LCZ 2).

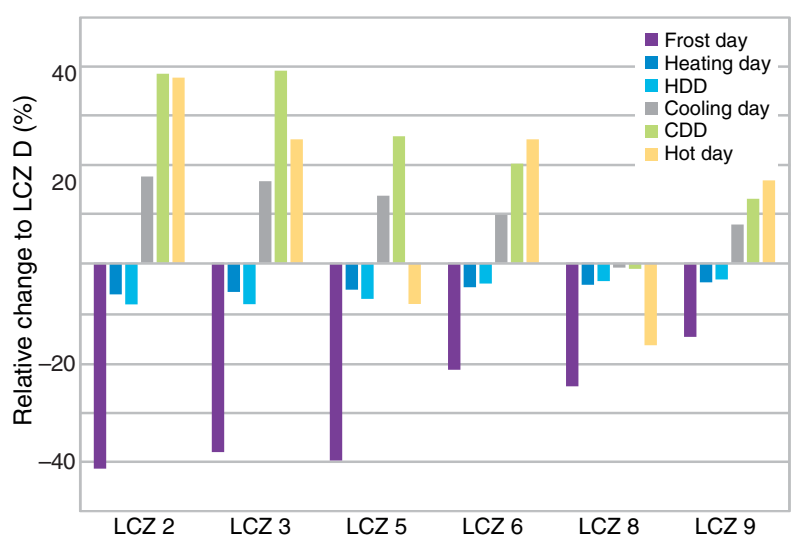

Figure 3. Change in values for air temperature indices in LCZ classes, relative to LCZ D, for 2014-2015.

Table 6. Frequency of days and standard deviation among stations according to daily temperature indices and LCZ classes in Szeged (June 2014-May 2015).

\begin{tabular}{lccccccc}
\hline Daily temperature index $(2014-2015)$ & \multicolumn{5}{c}{ LCZ class (number of stations per class) } \\
\cline { 2 - 7 } & 2 & 3 & 5 & 6 & 8 & 9 & $\mathrm{D}$ \\
& $(1)$ & $(1)$ & $(4)$ & $(9)$ & $(1)$ & $(2)$ & $(2)$ \\
\hline Frost days $\left(T_{\min }<0^{\circ} \mathrm{C}\right)$ & 35 & 37 & 36 & 47 & 45 & 51 & 60 \\
$($ standard deviation) & $(-)$ & $(-)$ & $(1.6)$ & $(3.7)$ & $(-)$ & $(2.1)$ & $(4.9)$ \\
Heating days $\left(T_{\operatorname{mean}}<15^{\circ} \mathrm{C}\right)$ & 190 & 191 & 192 & 193 & 194 & 195 & 203 \\
$($ standard deviation) & $(-)$ & $(-)$ & $(1.1)$ & $(3.0)$ & $(-)$ & $(4.2)$ & $(4.9)$ \\
$\mathrm{HDD}\left({ }^{\circ} \mathrm{C}\right)$ & 1585 & 1586 & 1605 & 1658 & 1667 & 1673 & 1731 \\
$($ standard deviation) & $(-)$ & $(-)$ & $(23.1)$ & $(36.4)$ & $(-)$ & $(6.4)$ & $(16.2)$ \\
Cooling days $\left(T_{\operatorname{mean}}>18.3^{\circ} \mathrm{C}\right)$ & 121 & 120 & 117 & 113 & 102 & 111 & 103 \\
$($ standard deviation) & $(-)$ & $(-)$ & $(1.1)$ & $(3.6)$ & $(-)$ & $(6.4)$ & $(4.2)$ \\
$\mathrm{CDD}\left({ }^{\circ} \mathrm{C}\right)$ & 448 & 450 & 407 & 389 & 320 & 366 & 324 \\
$($ standard deviation) & $(-)$ & $(-)$ & $(10.7)$ & $(17.7)$ & $(-)$ & $(24.0)$ & $(30.4)$ \\
Hot days $\left(T_{\max }>30^{\circ} \mathrm{C}\right)$ & 33 & 30 & 22 & 30 & 20 & 28 & 24 \\
$($ standard deviation) & $(-)$ & $(-)$ & $(1.8)$ & $(2.4)$ & $(-)$ & $(8.5)$ & $(0.7)$ \\
Tropical nights $\left(T_{\min }>20^{\circ} \mathrm{C}\right)$ & 14 & 18 & 10 & 4 & 5 & 3 & 0 \\
$($ standard deviation) & $(-)$ & $(-)$ & $(3.2)$ & $(2.1)$ & $(-)$ & $(0.7)$ & $(0)$ \\
\hline
\end{tabular}


(a)

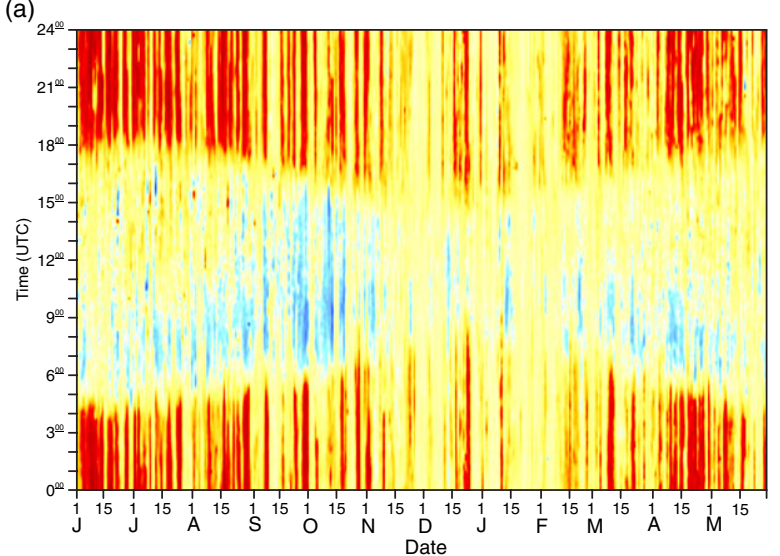

(b)

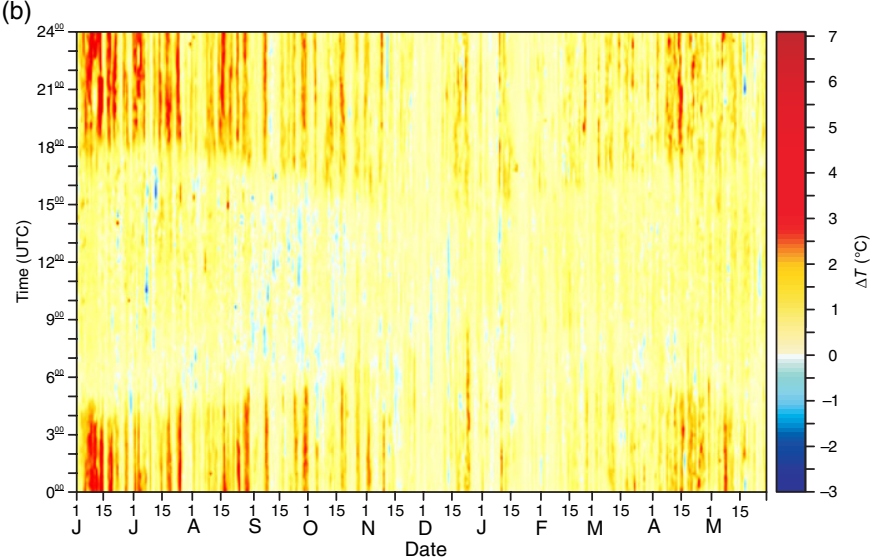

Figure 4. Annual and diurnal air temperature differences between LCZ classes in Szeged. (a) $\Delta \mathrm{T}_{\mathrm{LCZ} 3-\mathrm{LCZ} \text { D }}$ ( (b) $\Delta \mathrm{T}_{\mathrm{LCZ} \text { 6-LCZ D }}$ (June 2014-May 2015).

For the 'warm' indices (i.e. those indicating high temperatures), the greatest inter-class LCZ differences are among tropical nights: the number of days increases with the density of the built environment (and thus decreases with the fraction of pervious or green surfaces). LCZs 2 and 3 experience 14-18 tropical nights, compared to just 3 in LCZ 9 (sparsely built). This corresponds to a $600 \%$ increase from city outskirts to city centre (Table 6).

\subsubsection{Urban-rural temperature differences}

We used station HMS (LCZ D) to represent rural temperatures, and to compare those temperatures to average values in two urbanized areas of the city: one of compact form (LCZ 3), and the other of open form (LCZ 6). In the case of LCZ 3, the values are derived from one station, but for LCZ 6 they are averages of multiple stations. Annual and diurnal variations in temperature differences between the LCZ classes ( $\left.\Delta T_{\mathrm{LCZ} X-\mathrm{LCZ} \mathrm{D}}\right)$ are presented as isopleths (Figure 4).

In both comparisons, the temperature differences between daytime and night-time hours, and between seasons, are apparent. Greater values appear during the shorter nights of the warmer months, but in the case of LCZ 3 , the variation of daily $\Delta T$ is more striking, especially from June to October: daytime values of $\Delta T_{\text {LCZ 3-LCZ D }}$ range from -1 and $-1.5^{\circ} \mathrm{C}$, while evening values commonly exceed $4^{\circ} \mathrm{C}$ (Figure $4(\mathrm{a})$ ). Temperature differences greater than $6^{\circ} \mathrm{C}$ occurred on a few nights in April and June several hours after sunset. There were long periods during the spring and summer months when relatively large $\Delta T$ values occurred (e.g. 16-28 April, 2-15 June, and 15-30 August). During these summer periods, daily maximum temperatures exceeded $30^{\circ} \mathrm{C}$. Such periods are commonly associated with uncomfortably hot daytime conditions in Szeged.

Daytime temperature differences are comparatively small, due to the variable shading effects of trees and closely spaced low- and midrise buildings, and to the higher and more turbulent atmospheric boundary layer typically observed over urban areas during the day (Oke,
1987; Theeuwes et al., 2015). Thus, daytime maxima in LCZs 3 and 6 are often lower than in open rural areas of low plants (LCZ D) (Figure 4). In the open and vegetated LCZ 6 class, heat storage is much lower than in the built-up LCZ 3 class, and thus maximum temperature differences with LCZ D rarely exceed $4^{\circ} \mathrm{C}$ (most commonly between April and October) (Figure 4(b)). Daytime negative values were rarely observed.

\subsection{Intra-class LCZ comparisons}

To test the robustness of the LCZ scheme and Szeged's monitoring network, we investigated the intra-class temperature differences and their possible causes for LCZs 5, 6, and 9, having 4, 9, and 2 stations, respectively, for the summer months (June to August). The evaluated time periods are the same as in Section 4.1.1. for the means of daily ( $24 \mathrm{~h}$ ), diurnal (sunrise to sunset), and nocturnal (sunset to sunrise) temperatures for ideal days in summer (JJA) $(n=12)$. The three LCZs show some intra-class variations of less than $1{ }^{\circ} \mathrm{C}$, day and night (Figure 5). Only in LCZ 6 do the nocturnal intra-class thermal differences exceed $1{ }^{\circ} \mathrm{C}$. These small variations among stations of the same class are likely due to peculiarities in the stations' microscale exposure, surface cover, and anthropogenic heat sources (e.g. vehicle traffic).

Daily and diurnal temperature differences $\left(0.1-0.3{ }^{\circ} \mathrm{C}\right)$ are negligible among the four stations of LCZ 5 (Figure 5). At night, the thermal differences are slightly larger (max. $0.8^{\circ} \mathrm{C}$ ). For LCZ 6, daily and diurnal values are very similar (maximum differences of only $0.5^{\circ} \mathrm{C}$ ) (Figure 5). At night, however, Station ALS is about $1.5^{\circ} \mathrm{C}$ warmer than station WAL. For the two stations in LCZ 9, temperature differences are greatest in daytime, reaching nearly $1^{\circ} \mathrm{C}$, and least at night $\left(0.4^{\circ} \mathrm{C}\right)$ (Figure 5).

Focusing only on nocturnal hours, the mean and mean maximum nocturnal temperature deviations from LCZ D (station HMS) (as a measure of UHI, or $\Delta \mathrm{T}$ ) for ideal days can be compared in summer months (Figure 6). For LCZ 5, the temperature deviations between stations for mean and maximum values are less than $1{ }^{\circ} \mathrm{C}$ in all cases, and for 


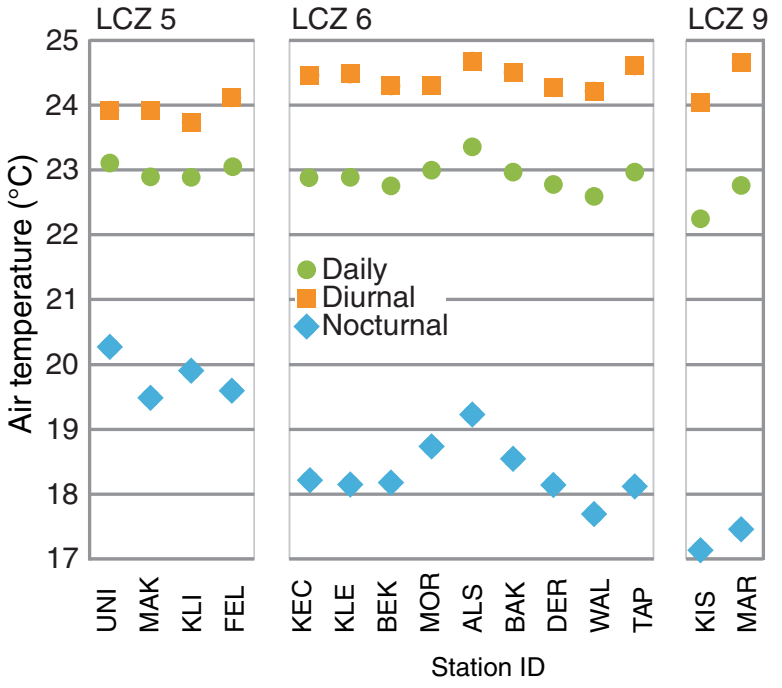

Figure 5. Daily (24h), diurnal (sunrise to sunset), and nocturnal (sunset to sunrise) air temperatures at meteorological stations during ideal days $(n=12)$ in Szeged (June-August 2014).
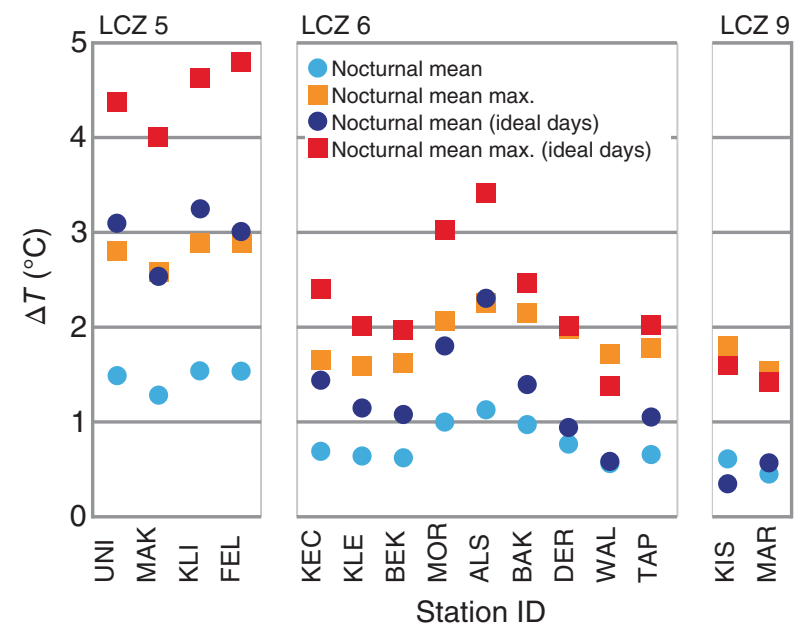

Figure 6. Intra-class air temperature deviations relative to LCZ D for ideal summer nights $(n=12)$ in Szeged (June-August 2014). Nocturnal mean is the yearly mean temperature difference $(\Delta T)$ for the night-time hours. Nocturnal mean maximum is the yearly mean of maximum temperature differences $(\Delta T)$ for the night-time hours.

LCZ 9, less than $0.5^{\circ} \mathrm{C}$. For LCZ 6 during ideal nights, stations MOR and ALS have anomalously high values, ranging from 0.5 to $2{ }^{\circ} \mathrm{C}$ above all other stations in the same LCZ class. Temperature difference between the two stations in LCZ 9 are negligible $\left(<0.5^{\circ} \mathrm{C}\right)$ on all occasions.

\subsection{Temporal dynamics of heating and cooling rates for LCZs}

The formation of UHIs is driven essentially by differences in urban and rural heating and cooling rates (Oke, 1987). Similarly, local thermal climates in cities are driven by differential heating and cooling of built and natural surfaces. During 'ideal' nights in the study period $(n=32)$, cooling rates among compact LCZs (LCZs 2 and 3) were much less than among open, vegetated zones (LCZs 6, 9, and
D) (Figure 7(c) and (d)). This differential gave rise to the formation of strong intra-class thermal differences, and to large heat island magnitudes, as defined by $\Delta T_{\mathrm{LCZ} X-\mathrm{LCZ} \mathrm{D}}$ (here the rural station HMS represents LCZ D). Strong heat islands developed at $2 \mathrm{~h}$ after sunset $(\Delta T$ as high as $3.4^{\circ} \mathrm{C}$ ), and were sustained throughout the night until 10 $\mathrm{h}$ after sunset, when UHI magnitudes dropped below $3^{\circ} \mathrm{C}$. After sunrise, LCZs 9 and D warmed more rapidly than the densely built-up zones such as LCZs 2 and 3. Thus, the heating and cooling rates following sunrise and sunset, respectively, for the open and vegetated LCZ classes well exceed those of the compact classes. These differentials allowed for pronounced temperature differences to form among the city's local urban environments, and between the city and its rural surroundings.

We highlight the night of 29 August 2014 for its exceptional weather conditions for UHI and LCZ formation. On this night, $\Phi_{w}$ was 0.9 , indicating clear skies and calm winds. Following sunset, LCZs 6, 9, and D cooled rapidly, dropping 3 to $4{ }^{\circ} \mathrm{Ch}^{-1}$ (Figure 7(f)). By comparison, the cooling rates of the more densely built-up LCZs fluctuated between 1 and $2{ }^{\circ} \mathrm{Ch}^{-1}$. The corresponding UHI magnitude therefore attained a maximum value of $5.4^{\circ} \mathrm{C}$ $\left(\Delta T_{\text {LCZ 2-LCZ D }}\right.$ ) (Figure 7(e)). After sunrise, LCZs 9 and D warmed at rates exceeding $3.5^{\circ} \mathrm{Ch}^{-1}$, while in LCZs 2, 3 , and 5 , warming rates were $2^{\circ} \mathrm{Ch}^{-1}$. For all $\mathrm{LCZ}$ classes, maximum UHI magnitudes were sustained for a duration of approximately $4 \mathrm{~h}$ (from 5 to $9 \mathrm{~h}$ after sunset). Magnitudes during this time ranged from 1 to $5^{\circ} \mathrm{C}$, depending on which $\mathrm{LCZ}$ pairs are used to define the heat island. A discernible heat island first appeared 1-2 $\mathrm{h}$ after sunset $\left(\Delta T=2-4^{\circ} \mathrm{C}\right)$, and remained strong until $11 \mathrm{~h}$ after sunset, thereafter dropping sharply until the end of the observation period. On this exemplary night, the magnitude of the heat island in every LCZ class remained strong and consistent for at least $8 \mathrm{~h}$.

\section{Discussion}

Inter-class comparisons are necessary to evaluate the LCZ scheme and to assess the representativeness of the Szeged monitoring sites. Our results suggest that temperature observations from the monitoring sites meet expectation, such that each LCZ class has a unique thermal signal. Based on the 1-year dataset from Szeged, measurement sites within the same LCZ class exhibit temperature regimes more similar to each other than to sites in other classes. Maximum thermal differences among LCZ classes are observed during 'ideal' nights that favour differential cooling of urban and rural surfaces. This points to the development of a distinct 'urban' climate in Szeged. The observed mean temperature difference between LCZs 2 and $\mathrm{D}$, for example, approaches the expected temperature increase caused by anthropogenic climate change to the end of the 21st century in Hungary, which is $1.4^{\circ} \mathrm{C}$ (compared with the normal for 1961-1990) (Bartholy et al., 2007). During daytime, temperature differences among all classes are generally small, due to variable sun/shade 
(a) 3

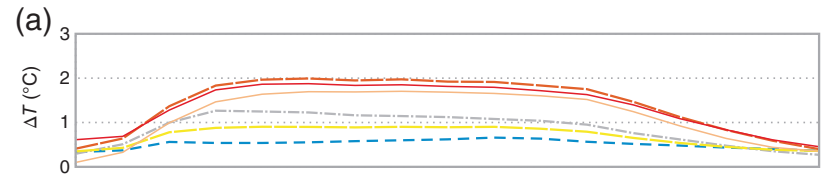

(c)

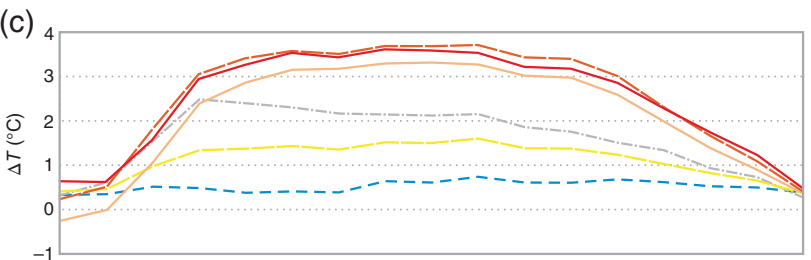

(e)

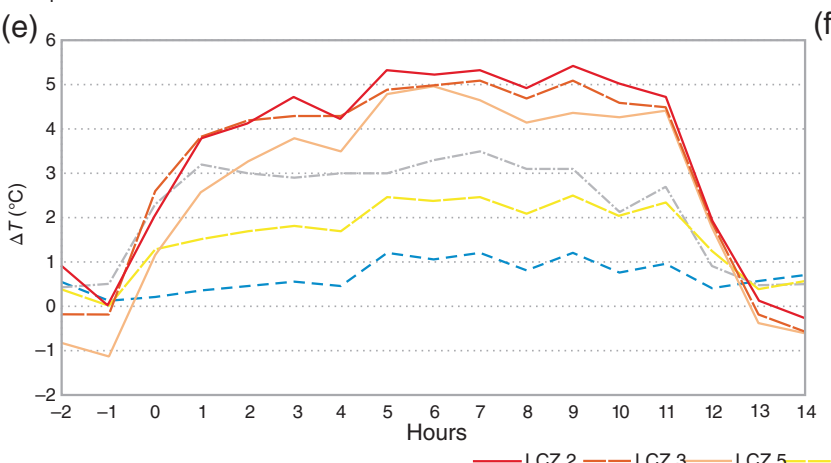

(b)

(d)
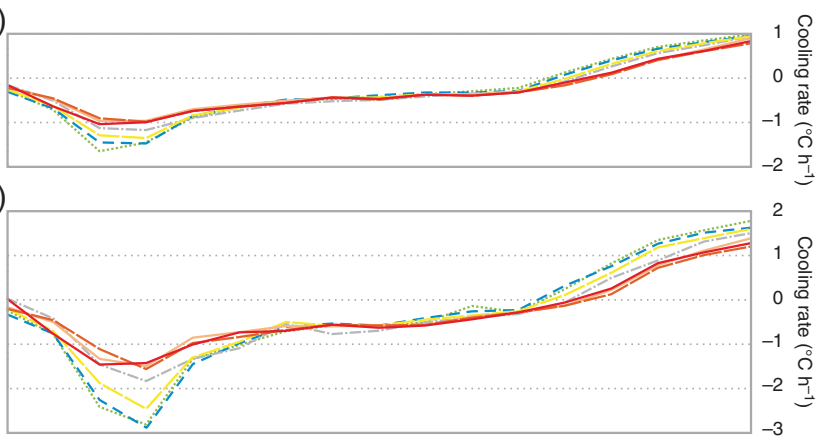

(f)

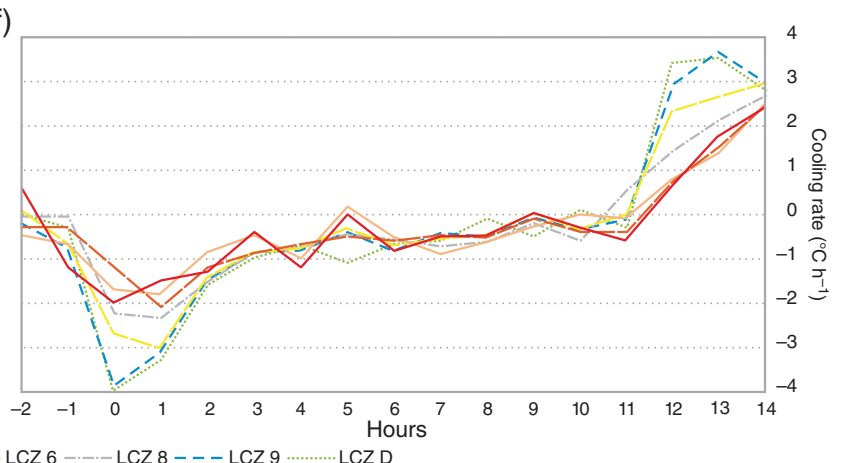

Figure 7. Nocturnal variation (from sunset-2 h to sunset $+14 \mathrm{~h}$ ) of the mean air temperature difference between LCZ classes $\left(\Delta T_{\mathrm{LCZ}} X-\mathrm{LCZ} \mathrm{D}\right.$, where $X=2,3,5,6,8,9)$ and their mean hourly heating and cooling rates. (a and b): Yearly means; (c and d): ideal days ( $n=32) ;(\mathrm{e}$ and $\mathrm{f})$ : 29 August 2014.

effects at the individual stations, and to greater mixing of the surface-layer air during afternoon hours when ground heating is favoured (Oke, 1987).

Intra-class thermal differences can be explained partly by the locations of the stations within the urban area: for example, for stations in LCZ 5, UNI, and KLI are located in the old core of Szeged, but MAK and FEL are located further out from the city centre, in areas characterized by 'blocks of flats'. We expect that these peripheral areas are exposed to local advection of cool air from the countryside during calm, clear nights when the heat island is most pronounced (Figure 1, Table 1). This local-scale circulation is known as the 'country breeze' and it is induced by strong heat island effects (Oke, 1987). LCZ 6 has the greatest intra-zone temperature variance among the three classes shown in Figure 6. This can again be explained by the location of the stations relative to the urban-rural boundary (Figure 1). Station ALS is centrally located away from the rural edge of the city and the cooling effects of a country breeze, and thus it is exposed to a larger urbanized fetch than station WAL.

Our chosen temperature-based indices for Szeged reveal strong differences among LCZ classes. Variance in the number of frost days, CDD, and tropical nights within Szeged is apparent, and is related to the spatial distribution of LCZ classes across the city. These indicators and their associated LCZ metadata can help city planners to apply simple principles of urban climatology to the design of more comfortable and efficient cities. With implications for urban agriculture, energy use, water consumption, infrastructure maintenance, and human thermal comfort, the indicators and their designated LCZ classes are easily communicated to, and understood by, workers in other disciplines that can benefit from 'value-added' urban climate information.

Our study has analysed nocturnal cooling rates in the LCZ classes of Szeged and its countryside. In general, the higher night-time temperatures of the built-up classes are due to the slow cooling rates of the urban surface (buildings and impervious cover), caused by increased heat storage, decreased heat release, and effective 'trapping' of longwave radiation in street canyons (Oke, 1987). Consistent with prior knowledge of heat island genesis and urban/rural heating and cooling rates, our results show that the greatest difference in thermal behaviour of LCZ classes occurs around sunset (Oke and Maxwell, 1975; Arnfield, 1990; Holmer et al., 2007). In Szeged, cooling rates among LCZ classes diverge markedly $1 \mathrm{~h}$ prior to sunset, lasting until $3 \mathrm{~h}$ after sunset; cooling rates then converge for the remainder of the night. These findings agree with recent results for the LCZ classes of Nancy, France (Leconte et al., 2016). Researchers have hypothesized that such divergent cooling rates around sunset are due to site-specific conditions that drive radiative flux divergence in the canopy layer (e.g. SVF), but that the more consistent cooling for the remainder of the night is influenced by radiative flux divergence at the inversion cap above the canopy layer (Holmer et al., 2007; Onomura et al., 2016).

In the early night-time hours, each LCZ class attains a unique thermal signal that is sustained throughout the morning hours until sunrise. Thus the temporal evolution of LCZs in the city resembles that of UHIs. By this resemblance, LCZs help to standardize the measurement and documentation of heat island magnitudes, and promote 
Table 7. Summary of results from the observational literature on LCZ temperature measurements in European cities.

\begin{tabular}{|c|c|c|c|c|c|c|c|}
\hline \multirow[t]{2}{*}{ City, country } & \multirow{2}{*}{$\begin{array}{l}\text { Investigated period } \\
\text { Number of days }(n) \\
\text { Fixed/mobile } \\
\text { measurements (f/m) }\end{array}$} & \multicolumn{6}{|c|}{ LCZ temperature differences } \\
\hline & & $2-D$ & $3-D$ & $5-\mathrm{D}$ & $6-\mathrm{D}$ & $8-\mathrm{D}$ & 9_D \\
\hline $\begin{array}{l}\text { Uppsala, Sweden; } \\
\text { Stewart and Oke } \\
\text { (2010) }\end{array}$ & September $(n=1, \mathrm{f})$ & 4.6 & - & 2.9 & 1.4 & - & 1.6 \\
\hline \multirow{5}{*}{$\begin{array}{l}\text { Uppsala, Sweden; } \\
\text { Stewart (2011b) }\end{array}$} & April $(n=1, \mathrm{~m})$ & 3.4 & - & 3.2 & 2.4 & - & 1.6 \\
\hline & June $(n=1, \mathrm{~m})$ & 5.0 & - & 3.5 & 2.1 & - & 1.7 \\
\hline & July $(n=1, \mathrm{~m})$ & 3.8 & - & 2.7 & - & - & 2.7 \\
\hline & $\operatorname{Nov}(n=1, \mathrm{~m})$ & 5.9 & & 5.1 & & & 4.3 \\
\hline & $\operatorname{March}(n=1, \mathrm{~m})$ & 4.9 & & 3.9 & & & 3.6 \\
\hline \multirow{2}{*}{$\begin{array}{l}\text { Szeged, Hungary; } \\
\text { Unger et al. (2014) }\end{array}$} & Annual $(n=35, \mathrm{~m})$ & 2.6 & 2.5 & 2.0 & 1.3 & 2.1 & 0.9 \\
\hline & $\operatorname{March}(n=1, \mathrm{~m})$ & 5.6 & 4.6 & 3.3 & 1.2 & 3.1 & 0.1 \\
\hline $\begin{array}{l}\text { Dublin, Ireland; } \\
\text { Alexander and Mills } \\
\text { (2014) }\end{array}$ & August $(n=1, \mathrm{f})$ & 4.8 & 4.0 & 3.2 & 2.9 & 3.1 & - \\
\hline \multirow{3}{*}{$\begin{array}{l}\text { Uppsala, Sweden; } \\
\text { Stewart et al. (2014) }\end{array}$} & Annual $(n=31, \mathrm{~m})$ & 3.2 & - & 2.2 & - & - & 1.9 \\
\hline & May-September $(n=17, \mathrm{~m})$ & 2.8 & & 2.0 & & & 1.8 \\
\hline & October-March $(n=14, \mathrm{~m})$ & 3.5 & & 2.6 & & & 2.1 \\
\hline $\begin{array}{l}\text { Nancy, France; } \\
\text { Leconte } \text { et al. (2015) }\end{array}$ & Summer $(n=9$ to $17, \mathrm{~m})$ & 4.4 & - & 4.2 & $2.4^{\mathrm{a}}$ & 2.9 & $2.4^{\mathrm{a}}$ \\
\hline \multirow{10}{*}{$\begin{array}{l}\text { Szeged, Hungary (this } \\
\text { study); mean daily } \\
\text { max. difference }\end{array}$} & Annual $(n=365, \mathrm{f})$ & 2.9 & 3.0 & 2.8 & 1.9 & 2.0 & 1.7 \\
\hline & Summer $(n=92, \mathrm{f})$ & 3.6 & 3.8 & 3.4 & 2.4 & 3.0 & 1.9 \\
\hline & Autumn $(n=91, \mathrm{f})$ & 2.6 & 2.7 & 2.6 & 1.7 & 1.9 & 1.6 \\
\hline & Winter $(n=90, \mathrm{f})$ & 2.2 & 2.2 & 2.1 & 1.4 & 1.3 & 1.5 \\
\hline & Spring $(n=92, \mathrm{f})$ & 3.4 & 3.6 & 3.3 & 2.2 & 2.4 & 1.9 \\
\hline & Annual ideal days $(n=32, \mathrm{f})$ & 4.5 & 4.5 & 4.4 & 2.3 & 2.9 & 1.5 \\
\hline & Summer ideal days $(n=12, \mathrm{f})$ & 4.8 & 4.7 & 4.6 & 2.7 & 3.3 & 1.7 \\
\hline & Autumn ideal days $(n=10, \mathrm{f})$ & 4.6 & 4.7 & 4.7 & 2.4 & 3.1 & 1.6 \\
\hline & Winter ideal days $(n=5, \mathrm{f})$ & 3.3 & 3.3 & 3.2 & 1.8 & 2.0 & 1.6 \\
\hline & Spring ideal days $(n=5, \mathrm{f})$ & 4.3 & 4.1 & 3.8 & 1.9 & 3.4 & 0.8 \\
\hline
\end{tabular}

Values represent nocturnal air temperature differences between LCZ classes (i.e. $\Delta T_{\mathrm{LCZ} X-\mathrm{LCZ} \text { D }}$, where $X=1$ to 10$)\left({ }^{\circ} \mathrm{C}\right) .{ }^{\mathrm{a}} \mathrm{LCZ} 6 / 9$.

awareness of the small-scale climates that comprise the larger-scale UHI (Stewart and Oke, 2012). As a caveat, however, LCZ stations of the same class, but of various locations within the city, can produce different thermal signals. This is due to advection across dissimilar fetches of the surrounding land cover, and to local thermal circulations such as the country breeze. One must be aware of these influences when using LCZs to define UHI magnitude.

To generalize our findings, we compare the results from Szeged to those reported in previous LCZ studies of other European cities (Table 7). We acknowledge that such comparisons are limited by inter-study differences in sample size, observation periods, measurement control, instrument specifications, and city location. Despite these differences, we can identify general trends among the surveyed studies. While single values for LCZ temperature differences among same-class combinations are quite variable among cities, relative changes are fairly consistent. Temperature differences between compact classes and rural surroundings (i.e. $\Delta T_{\text {LCZ 2,3-LCZ D }}$ ) exceed those of open classes and rural surroundings $\left(\Delta T_{\mathrm{LCZ} 5,6-\mathrm{LCZ} D}\right)$; in all such cases, the sparsely settled areas of the city (LCZ 9) are the coolest (Table 7). LCZ 8 (large low-rise) is warmer, on average, than LCZs 6 and 9, and cooler than LCZs 2 and 3. Maximum temperature differences between LCZs 2 and D are approximately $6{ }^{\circ} \mathrm{C}$ for Szeged (Unger et al., 2014) and Uppsala, Sweden (Stewart, 2011b); $5^{\circ} \mathrm{C}$ for Dublin, Ireland (Alexander and Mills, 2014); and $4{ }^{\circ} \mathrm{C}$ for Nancy, France (Leconte et al., 2015) (Table 7). These inter-class temperature differences of $4-6^{\circ} \mathrm{C}$ are indicative of the maximum UHI intensities observed in medium-sized European cities characterized by compact midrise cores (LCZ 2) and pastoral surroundings (LCZs B and/or D).

Our study highlights the use of urban meteorological networks to monitor temperature conditions in cities. The 20-station network in Szeged is a prototype design: it was conceived with the principles of accuracy, security, and longevity in mind, and adheres to LCZ and WMO guidelines for station siting in urban areas (Oke, 2004; Stewart and Oke, 2012). The network thereby ensures that its users 
gain valuable insights into the local and micro-scale climatologies of Szeged. Given the level terrain of Szeged, and the automated operation of the network, we were able to control our measurements for non-urban influences on climate, and to isolate local urban effects on air temperature. The LCZ scheme gives the standard framework to relate those differences to changes in land cover, surface morphology, and human activity.

\section{Conclusions and outlook}

We have evaluated a 1-year temperature dataset from a 20-station meteorological network in Szeged, Hungary. The placement of stations was guided by the LCZ scheme and its recommendations for temperature studies in urban areas. Our stations were sited so as to be representative of the local area, and to allow observations of local temperatures under a range of weather conditions. We provided detailed site metadata for each station to improve our explanation of the observed temperatures, and to enable generalizations and inter-study comparisons of LCZs and their thermal characteristics. In few cases, our station metadata did not fit within the range of LCZ parameter values given by Stewart and Oke (2012), but this is normal for any urban meteorological network whose configuration is restricted by instrument safety, security, and accessibility.

Our primary goal was to analyse the long-term thermal conditions of LCZ classes in ideal and average weather conditions in Szeged. We observed that in compact LCZ classes, $T_{\text {mean }}$ and $T_{\text {min }}$ values increased above other classes, but no clear tendency was observed for $T_{\text {max }}$. Our evaluation of the yearly data shows that the strongest UHI effect (defined by $\Delta T_{\text {LCZ 3-LCZ D }}$ ) is a more frequent phenomenon in the warm period of the year as compared with the cooler period. We measured temperature indices for different LCZ classes within Szeged: 'frost days' were more frequent in areas of the city with natural cover and open structure, while 'tropical nights' were more frequent in areas of impervious cover and compact structure. Owing to such localized differences in air temperature, energy demand for building heating decreases toward the compact, built-up core of Szeged in the winter months, while in summer months the core experiences greater nocturnal cooling demand due to heat island effects. By reporting these results with standardized indices, definitions, and climatic classes, we encourage meaningful comparisons with other cities, and easy delivery of climate information to urban planners and local governments.

In conclusion, we urge researchers in other cities to implement similar urban networks based on explicit site-selection criteria, and on spatial designs that meet specific aims. The data gathered from such networks can serve many needs. In Szeged, the data can help meteorologists to develop and test specialized weather forecasts for local areas of the city, to include summer heat-stress alerts for residents and workers in the warmest areas (e.g. LCZ 2), and winter frost warnings for urban farmers and home gardeners in the coolest areas (e.g. LCZ 9). The network data can also assist utility managers to investigate the spatial and temporal characteristics of energy and water use among the city's many LCZs. We therefore hope, in the long term, that our meteorological network contributes to the planning process in Szeged, to ensure a more liveable and sustainable environment, and to inspire a more climate-sensitive perspective on urban design.

\section{Acknowledgements}

This study was supported by the Hungarian Scientific Research Fund (OTKA K-111768) and by National Research, Development and Innovation Office (NKFI K-120346). Tamás Gál was supported by the ÚNKP-16-4 New National Excellence Program of the Ministry of Human Capacities and by the János Bolyai Research Scholarship of the Hungarian Academy of Sciences.

\section{References}

Alexander PJ, Mills G. 2014. Local climate classification and Dublin's urban heat island. Atmosphere 5: 755-774, doi: 10.3390/atmos5040755.

Arnfield AJ. 1990. Canyon geometry, the urban fabric and nocturnal cooling: a simulation approach. Phys. Geogr. 11: 220-239.

Auer AH. 1978. Correlation of land use and cover with meteorological anomalies. J. Appl. Meteorol. 17: 636-643, doi: 10.1175/1520-0450(1978)017<0636:COLUAC>2.0.CO;2.

Balázs B, Unger J, Gál T, Sümeghy Z, Geiger J, Szegedi S. 2009. Simulation of the mean urban heat island using 2D surface parameters: empirical modeling, verification and extension. Meteorol. Appl. 16: 275-287, doi: 10.1002/met.116

Bartholy J, Pongrácz R, Gy G. 2007. Regional climate change expected in Hungary for 2071-2100. Appl. Ecol. Environ. Res. 5: 1-17.

Bechtel B, Daneke C. 2012. Classification of local climate zones based on multiple earth observation data. IEEE J. Select. Top. Appl. Earth Obs. Remote Sens. 5: 1191-1202, doi: 10.1109/JSTARS.2012.2189873.

Bechtel B, Alexander PJ, Böhner J, Ching J, Conrad O, Feddema F, Mills G, See L, Stewart ID. 2015. Mapping local climate zones for a worldwide database of the form and function of cities. ISPRS Int. J. GeoInf. 4: 199-219, doi: 10.3390/ijgi4010199.

Bolz HM. 1949. Die Abhängigkeit der Infraroten Gegenstrahlung von der Bewölkung. Meteorol. Z. 3: 201-203.

Fenner D, Meier F, Scherer D, Polze A. 2014. Spatial and temporal air temperature variability in Berlin, Germany, during the years 2001-2010. Urban Clim. 10: 308-331, doi: 10.1016/j.uclim.2014.02.004.

Gál T, Lindberg F, Unger J. 2009. Computing continuous sky view factor using $3 \mathrm{D}$ urban raster and vector data bases: comparison and application to urban climate. Theor. Appl. Climatol. 95: 111-123, doi: 10.1007/s00704-007-0362-9.

Holmer B, Thorsson S, Eliasson I. 2007. Cooling rates, sky view factors and the development of intra-urban air temperature differences. Geogr. Ann. Ser. A Phys. Geogr. 89A: 237-248.

Kottek M, Grieser J, Beck C, Rudolf B, Rubel F. 2006. World Map of the Köppen-Geiger climate classification updated. Meteorol. Z. 15: 259-263, doi: 10.1127/0941-2948/2006/0130.

Leconte F, Bouyer J, Claverie R, Pétrissans M. 2015. Using local climate zone scheme for UHI assessment: evaluation of the method using mobile measurements. Build. Environ. 83: 39-49, doi: 10.1016/j.buildenv.2014.05.005.

Leconte F, Bouyer J, Claverie R, Pétrissans M. 2016. Analysis of nocturnal air temperature in districts using mobile measurements and a cooling indicator. Theor. Appl. Climatol., doi: 10.1007/s00704-016-1886-7.

Lehnert M, Geletič J, Husák J, Vysoudil M. 2014. Urban field classification by "local climate zones" in a medium-sized Central European city: the case of Olomouc (Czech Republic). Theor. Appl. Climatol. 122: 531-541, doi: 10.1007/s00704-014-1309-6. 
Lelovics E, Unger J, Gál T, Gál CV. 2014. Design of an urban monitoring network based on local climate zone mapping and temperature pattern modelling. Clim. Res. 60: 51-62, doi: 10.3354/cr01220.

Lowry WP. 1977. Empirical estimation of the urban effects on climate: a problem analysis. J. Appl. Meteorol. 16: 129-135, doi: 10.1175/1520-0450(1977)016<0129:EEOUEO>2.0.CO;2.

Matzarakis A, Thomsen F. 2009. Heating and cooling degree days as an indicator of climate change in Freiburg. In 89th AMS Annual Meeting, Fourth Symposium on Policy and Socio-Economic Research, Phoenix, AZ, 8 pp.

Mizuno M, Nakamura Y, Murakami H, Yamamoto S. 1990/1991. Effects of land use on urban horizontal atmospheric temperature distributions. Energy Build. 15: 165-176.

Nakamura Y, Oke TR. 1988. Wind, temperature and stability conditions in an east-west oriented urban canyon. Atmos. Environ. 22: 2691-2700, doi: 10.1016/0004-6981(88)90437-4.

Oke TR. 1987. Boundary Layer Climates. Routledge: London and New York, NY.

Oke TR. 1998. An algorithmic scheme to estimate hourly heat island magnitude. In Preprints, 2nd Urban Environment Symposium, 2-6 November, Albuquerque, NM.

Oke TR. 2004. Initial guidance to obtain representative meteorological observation sites. WMO/TD No. 1250, World Meteorological Organization, Geneva, Switzerland.

Oke TR, Maxwell GB. 1975. Urban heat island dynamics in Montreal and Vancouver. Atmos. Environ. 9: 191-200.

Onomura S, Holmer B, Lindberg F, Thorsson S. 2016. Intra-urban nocturnal cooling rates: development and evaluation of the NOCRA model. Meteorol. Appl. 23: 339-352, doi: 10.1002/met.1558.

Runnalls KE, Oke TR. 2006. A technique to detect microclimate inhomogeneities in historical records of screen-level air temperature. $J$. Clim. 19: 959-978.

Siu LW, Hart MA. 2013. Quantifying urban heat island intensity in Hong Kong SAR, China. Environ. Monit. Assess. 185: 4383-4398, doi: 10.1007/s10661-012-2876-6.

Skarbit N, Gál T. 2016. Projection of intra-urban modification of night-time climate indices during the 21st century. Hung. Geograph. Bull. 62: $181-193$.
Stewart ID. 2011a. A systematic review and scientific critique of methodology in modern urban heat island literature. Int. J. Climatol. 31: 200-217, doi: 10.1002/joc.2141.

Stewart ID. 2011b. Redefining the Urban Heat Island. PhD dissertation, Department of Geography, University of British Columbia, Vancouver, Canada, $352 \mathrm{pp}$

Stewart ID, Oke TR. 2010. Thermal differentiation of local climate zones using temperature observations from urban and rural field sites. In Ninth Symposium on Urban Environment, August 2-6, American Meteorological Society: Keystone, CO.

Stewart ID, Oke TR. 2012. Local climate zones for urban temperature studies. Bull. Am. Meteorol. Soc. 93: 1879-1900, doi: 10.1175/BAMS-D-11-00019.1.

Stewart ID, Oke TR, Krayenhoff ES. 2014. Evaluation of the 'local climate zone' scheme using temperature observations and model simulations. Int. J. Climatol. 34: 1062-1080, doi: 10.1002/ joc. 3746 .

Theeuwes NE, Steeneveld GJ, Ronda RJ, Rotach MW, Holtslag AAM. 2015. Cool city mornings by urban heat. Environ. Res. Lett. 10 114022.

Unger J. 2009. Connection between urban heat island and sky view factor approximated by a software tool on a 3D urban database. Int. J. Environ. Pollut. 36: 59-80, doi: 10.1504/IJEP.2009. 021817.

Unger J, Sümeghy Z, Gulyás Á, Bottyán Z, Mucsi L. 2001. Land-use and meteorological aspects of the urban heat island. Meteorol. Appl. 8: 189-194, doi: 10.1017/S1350482701002067.

Unger J, Savic S, Gál T. 2011. Modelling of the annual mean urban heat island pattern for planning of representative urban climate station network. Adv. Meteorol. 2011: 9, doi: 10.1155/2011/398613.

Unger J, Lelovics E, Gál T. 2014. Local Climate Zone mapping using GIS methods in Szeged. Hung. Geograph. Bull. 63: 29-41, doi: 10.15201/hungeobull.63.1.3.

Unger J, Gál T, Csépe Z, Lelovics E, Gulyás Á. 2015. Development, data processing and preliminary results of an urban human comfort monitoring and information system. Idójárás 119: 337-354.

URBAN-PATH homepage. 2015. http://urban-path.hu/ (accessed 1 March 2016) 